\title{
Endovaginal Ultrasound versus Hysterosalpingography in Evaluation of Cesarean Scar
}

\author{
Mohamed E Anter*, Mohamed S. Gad, Emily M. Fahmy, Alla Aldeen A. Al Halaby \\ Obstetrics and Gynecology Department, Faculty of Medicine, Menoufia University, Menoufia, Egypt \\ *Corresponding Author: Mohamed Elsibai Anter, Mobile: 01009737067, E-Mail: mohamedsibai681@ yahoo.com
}

\begin{abstract}
Background: Cesarean section (CS) is one of the most common surgical procedures in women. A recent study documented that Egypt ranked $3^{\text {rd }}$ among world countries with an estimated rate of CS of $51.8 \%$.

Objective: We aimed to evaluate uterine scar after cesarean section (CS) by transvaginal ultrasound (TVS) versus hysterosalpingogram (HSG).

Patient and methods: This cross-sectional study was conducted on 38 patients after obtaining their approval to evaluate CS scar 3 months after delivery using TVS compared to HSG. The study was conducted in Obstetrics and Gynecology Department, Menoufia University in the period between January 2019 and January 2020.

Results: Uterine scar defect was identified in 21 cases by HSG (55.3\%), while TVS was able to identify it in only 13 cases (34.2\%). Compared to HSG, transvaginal ultrasound had sensitivity and specificity of 61.9 and $100 \%$ respectively in detecting scar defects, with an accuracy of $78.94 \%$,

Conclusion: Along with increased radiological expertise expected with time, TVS will be more comparable to HSG and appears to be a promising tool in evaluation cesarean scar defect as it has significant agreement with HSG.
\end{abstract}

Keywords: Cesarean Section, Cross-Sectional Studies, Hysterosalpingography, Ultrasonography.

\section{INTRODUCTION}

Cesarean scar defect (CSD) indicates the presence of a hypoechoic region within the myometrium in the isthmus (the lower part of the uterus) with the myometrium stopping at the site of the previous CS scar ${ }^{(\mathbf{1})}$. Patients who had a previous caesarean section should be evaluated for CSD. The best time is after the patient's menstrual cycle, when the endometrium is at its thinnest and the menstrual blood has recently collected in the defect (this can highlight imaging) ${ }^{(2)}$.

There are several imaging techniques to detect the CSD but there is no universal consensus about which is the gold standard. Moreover, there are no standardized diagnostic criteria. TVS or salineinfusion sonohysterogram serves as a first-line test for in-office diagnosis. MRI, 3D US and hysteroscopy are additional useful imaging modalities that can aid in the diagnosis ${ }^{(3)}$. HSG is the radiographic evaluation of the uterus and fallopian tubes and is used predominantly in the evaluation of infertility. Ultrasonography is currently used for evaluation of the endometrium and pregnancy, whereas MRI is used more in the evaluation of the uterine myometrium and the ovaries. In our practice, the number of HSG examinations has increased dramatically over the past few years ${ }^{(4)}$.

TVS is a first level and widely used imaging technique. CSD is described as an anechoic, triangular shape defect with apex pointing anteriorly, located at the anterior uterine wall ${ }^{(5)}$. Evaluation of the CS scar is performed to choose the technique of future delivery and prevention of uterine rupture and in cases of abnormal bleeding after delivery ${ }^{(6)}$. To our knowledge, there is a dearth of studies comparing TVS to HSG in uterine scar defects. However, the existing literature is rich in reports assessing the role of ultrasound in evaluating the lower part of the uterus and its scars ${ }^{(7)}$.

The aim of the current study was to evaluate TVS versus HSG in the evaluation of uterine scar after cesarean section.

\section{PATIENT AND METHOD}

This cross-sectional study was conducted in Obstetrics and Gynecology Department Menoufia University in the period from January 2019 to January 2020. The study included 38 participants (all were selected from patients attending the departmental outpatient clinic according to sample size calculation).

\section{Ethical approval:}

Our study received the approval of the local Ethical Committee of Faculty of Medicine, Menoufia University. A written informed consent was obtained from all participants before starting the procedure after explanations the steps and the potential complications of each diagnostic modality. Study group was selected regarding the appropriate inclusion and exclusion criteria. Inclusion criteria: age between $20-40$ years, with regular menstrual cycles and had previous one cesarean section within a year. Exclusion criteria: patients with uterine pathology observed during TVS examination as endometrial polyp or submucous fibroid and patients with more than one previous cesarean section. 
All women included in the study were subjected to routine history and physical examination including personal history (name, age, occupation, marital status, number of children and any special habits of medical importance), menstrual history (duration of menstrual flow, frequency, regularity, dysmenorrhea and date of LMP), obstetrics history (gravidity, parity and abortion), sexual history (coital frequency and dyspareunia), past history (including hypertension, DM, PID, TB and pelvic surgery), family history (hypertension and diabetes), physical examination (including general examination, BMI, pulse, temperature, blood pressure, chest, heart, abdominal and lower limb examination), local gynecological examination (of the vulva, vagina, cervix and adnexa).
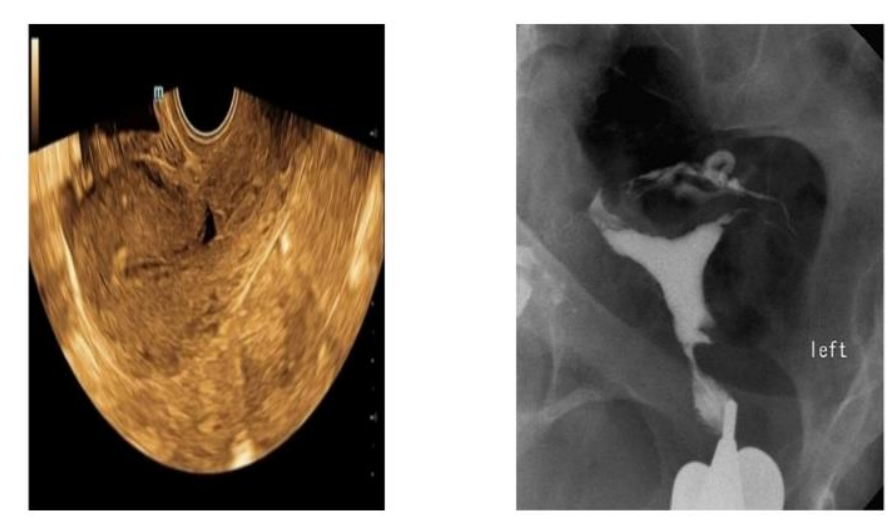

A

B

Figure (1): A: Transvaginal ultrasound (TVU) showing small cesarean scar defect in anterior uterine wall. B: HSG showing a wedge shape defect seen in the lower uterine cavity.

All patients underwent both TVS and HSG examination (Figure 1A and B) and they were examined by the same obstetric team with standard procedure. Using TVS (IBE Sonata plus ultrasound systems, China) the CS scar was measured in three dimensions (length, width and depth) in both sagittal and transverse planes. The CS scar was defined as a hypoechoic indentation at the anterior wall of the lower uterine segment (LUS), measurable in three dimensions and lying between the uterovesical fold and the internal cervical os. The scar appeared halfway between the uterovesical fold and the internal cervical os. The depth of the scar defect (D) was defined as the distance between the surface of the endometrial/endocervical layer of the posterior uterine wall to the tip of the hypoechoic triangle. The width (W) was defined as the distance between the proximal and distal parts of the myometrium of the anterior uterine wall measured at the surface of the endometrium/endocervix of the posterior uterine wall.
The residual myometrial thickness (RMT) was defined as the distance between the tip of the hypoechoic triangle and the surface of the anterior uterine wall. Thus, RMT represents the thickness of the myometrial layer at the site of hysterotomy and the morphological appearances of the scar was classified as mild, moderate and severe based on the value of mean scar defect. HSG was performed during the proliferative phase, after cessation of menstruation and before ovulation as the endometrium was thin in this time, so the image obtained was better interpreted.

The patient was placed on a radiographic table in a lithotomy position. After insertion of the speculum, the cervix was grasped with a tenaculum at 12 o'clock and brought forward to straighten the uterus. After cleansing the external os with povidone-iodine solution, the cervical os was cannulated with a hysterosalpingography balloon catheter to instill the contrast media (Visipaque 320 $\mathrm{mg} / \mathrm{ml}$ ) into the cervix. All air bubbles were removed from the cannula before injection. Under fluoroscopic monitoring, at least four images were obtained routinely. The best time to evaluate the shape of the uterus was when the uterus was filled completely. The defects were categorized by location (lower uterine segment, uterine isthmus, upper endocervical canal), and side (right, left, bilateral, small midline).

Sample size calculation: Based on population size of 200 cases with cesarean section at $95 \%$ confidence interval and $80 \%$ power of the study sample size calculation revealed 38 cases ${ }^{(8)}$.

\section{Statistical analysis}

Data were collected, tabulated and statistically analyzed using SPSS 22.0 for windows (SPSS Inc., Chicago, IL, USA) and Med Calc 13 for windows (Med Calc Software, Ostend, Belgium). Qualitative data were described using number and percent and were compared by $\mathrm{Chi}^{2}$ test. Quantitative data were described using mean, standard deviation (SD), median, range, and interquartile range (IQR). The diagnostic value indices including the specificity, sensitivity, positive and negative predictive values as well as accuracy for the results of TVU and HSG were calculated. Significance of the obtained results was judged at the (0.05) level.

\section{RESULT}

Our study included 38 participants. The mean age of the included cases was 23.36 years (Table 1). 
Table (1): Age, body mass index, and duration since CS of studied group

\begin{tabular}{|l|l||}
\hline & $\begin{array}{l}\text { Studied group } \\
\text { No }=38\end{array}$ \\
\hline Age (years) & \\
Mean \pm SD & $23.63 \pm 2.26$ \\
Median & 24 \\
Range & $20-31$ \\
IQR & $22.75,25$ \\
\hline BMI (kg/m $\left.{ }^{2}\right)$ & \\
Mean \pm SD & $27.2 \pm 2.37$ \\
Median & 27.56 \\
Range & $23.1-31.25$ \\
IQR & $24.80,29.70$ \\
\hline Duration since CS (years) & \\
Mean $\pm S D$ & $2.3 \pm 0.76$ \\
Median & 2 \\
Range & $0.5-4.5$ \\
IQR & $1.24-3.71$ \\
\hline
\end{tabular}

SD: standard deviation.

BMI: body mass index.

Table 2 shows the uterine position in the studied subjects (Table 2).

Table (2): Uterine position in the studied subjects

\begin{tabular}{||l|l|l|}
\hline \multirow{2}{*}{} & \multicolumn{2}{l|}{$\begin{array}{l}\text { Studied group } \\
\text { No }=\mathbf{3 8}\end{array}$} \\
\cline { 2 - 3 } & No & \% \\
\hline Anteflexion & 23 & 60.5 \\
\hline Retroflexion & 15 & 39.5 \\
\hline
\end{tabular}

Uterine scar defect as detected by HSG and TVS is shown in table 3 .

Table (3): Uterine scar defect as detected by hysterosalpingography and transvaginal ultrasound

\begin{tabular}{||l|l|l||}
\hline \multicolumn{1}{|c|}{} & \multicolumn{2}{l|}{$\begin{array}{l}\text { Studied group } \\
\text { No }=\mathbf{3 8}\end{array}$} \\
\cline { 2 - 3 } & No & \% \\
\hline $\begin{array}{l}\text { Transvaginal } \\
\text { ultrasound (TVS) } \\
\text { Present } \\
\text { Absent }\end{array}$ & 13 & \\
\hline $\begin{array}{l}\text { Hysterosalpingography } \\
\text { (HSG) }\end{array}$ & 25 & 64.2 \\
Present & & \\
Absent & 21 & 55.3 \\
\hline $\mathrm{X}^{2}$ & 17 & 45.7 \\
\hline P value & 3.41 \\
\hline
\end{tabular}

Diagnostic profile of TVS for diagnosis of uterine scar defect compared to HSG as the gold standard is shown in table 4.
Table (4): Diagnostic profile of transvaginal ultrasound (TVS) for diagnosis of uterine scar defect compared to Hysterosalpingography (HSG) as the gold standard

\begin{tabular}{|c|c|c|c|}
\hline \multirow{4}{*}{$\begin{array}{l}\text { Ultrasound } \\
\text { (TVS) }\end{array}$} & \multicolumn{3}{|c|}{ Hysterosalpingography (HSG) } \\
\hline & & Positive & Negative \\
\hline & Positive & 13 & 0 \\
\hline & Negative & 8 & 17 \\
\hline \multicolumn{4}{|c|}{ Diagnostic performance } \\
\hline Sensitivity & \multicolumn{3}{|c|}{$61.9 \%$} \\
\hline Specificity & \multicolumn{3}{|c|}{$100 \%$} \\
\hline PPV & \multicolumn{3}{|c|}{$68.0 \%$} \\
\hline NPV & \multicolumn{3}{|c|}{$100 \%$} \\
\hline Accuracy & \multicolumn{3}{|c|}{$78.94 \%$} \\
\hline
\end{tabular}

PPV: positive predictive values

NPV: negative predictive values

\section{DISCUSSION}

Caesarean scar defects (CSD) can be identified using high resolution TVS. The ultrasound features include myometrial thinning with a demonstrable defect in the myometrium noted on TVS or scar dehiscence at the level of the lower anterior myometrium in women who have undergone previous $\mathrm{CS}^{(\boldsymbol{9})}$.

The mean age in our study was 23.36 years. Fiocchi et al. ${ }^{(\mathbf{1 0})}$ reported older age (in the $3^{\text {rd }}$ decade). This could be explained by two facts, most of the previous studies included females with previous two and three previous CS, and that would definitely increase the age range. It is possible that examination around the time of menstrual bleeding or during the periovulatory period is affected by the increased intrauterine fluid, thus leading to higher sensitivity for some subtle defects which might have gone undetected on a scan during the dry phase of the cycle.

In our study, regarding the uterine position, 23 cases had anteflexed uterus (60.5\%) and 15 cases had retroflexed uterus $(39.5 \%)$. Vikhareva Osser and coworkers $^{(11)}$ reported also a higher prevalence of anteflexed uterus that was present in $80 \%$ of cases with previous one CS. They made a study of agreement between transvaginal sonographic findings with and without saline contrast enhancement and this coincides with our findings. Ofili- Yebovi et al. ${ }^{(12)}$ suggested that mechanical tension of the lower uterine segment in a retroflexed uterus might impair blood perfusion and oxygenation of the healing tissues, and that this could affect wound healing negatively.

In the current study, HSG was able to detect CS scar defects in 21 cases (55.3\%). Defects in CS are common, and the prevalence of scar defects and large scar defects increases with the number of CS. TVS 
was able to identify cesarean defect in only 13 cases $(34.2 \%)$.

Vikhareva Osser and coworkers ${ }^{(11)}$ reported that TVS was able to detect uterine scar in all cases with previous one CS. However, defect was identified in only $61 \%$ of these subjects. Tissue oxygenation is an important factor for wound healing (13). This seems natural, because healing conditions are likely to be poorer in tissue where there is already a scar $(14,15)$. In a study done by Monteagudo and coworkers $^{(16)}$ they detected scars defect at unenhanced ultrasound examination in only onethird (14/44) of women who had undergone CS. Armstrong and his associates reported that defect was visualized in 13 of 31 subjects (42\%) with a prior cesarean delivery ${ }^{(\mathbf{1 7})}$.

Regarding mean residual myometrial thickness in our study was $8.37 \mathrm{~mm}$. The agreement was good (percentage agreement varying from 88 to $100 \%$ and with Cohen's kappa varying from 0.679 to 1.000 ). The authors concluded that CSD were better evaluated through saline contrast enhancement TVUS than with unenhanced ultrasound examination, because the demarcations of scar defects were more clearly delineated, more defects were detected, and more defects were classified as large at saline contrast-enhanced TV-US. These findings can be explained by possible washing away of mucus from the niche during saline infusion. So, some authors recommend this technique especially in the surgical planning (18-20). However, it is more invasive, carries a small risk of complications (such as infections) and can overestimate the defect (about 1-2 mm) because of over-distention of the niche ${ }^{(\mathbf{2 1})}$.

All in all, with time, transvaginal US is expected to be the gold standard tool in evaluating cesarean scar defects. However, long radiological training is required. In addition, some authors suggest that TVUS evaluation of LUS should be combined with other information (previous singlelayer closure of the uterus or inter-delivery interval) and such a multifactorial system seems to better predict the occurrence of uterine rupture during trial of labour ${ }^{(22)}$.

Our study has some limitations: the relatively small sample size, it is a single center study and the long-term outcome of these defects should have been evaluated as well. Hence, the upcoming studies should cover these perspectives.

\section{CONCLUSION}

Based on our findings, transvaginal US appears to be a promising tool in evaluation post cesarean section scar defects. It has significant agreement with hysterosalpingogram. However, it should be performed by a high experienced specialist to increase the accuracy of detection.

\section{REFERENSES}

1. Gonzalez N, Tulandi $\mathbf{T}$ (2017): Cesarean scar pregnancy: a systematic review. Journal of Minimally Invasive Gynecology, 24(5):731-8.

2. Omidiji O, Toyobo O, Adegbola O et al. (2019): Hysterosalpingographic findings in infertility-what has changed over the years?. African Health Sciences, 19(2):1866-74.

3. Dreyer K, Van Rijswijk J, Mijatovic V et al. (2017): Oil-based or water-based contrast for hysterosalpingography in infertile women. New England Journal of Medicine, 376(21):2043-52.

4. Antila R, Mäenpää J, Huhtala H et al. (2020): Association of cesarean scar defect with abnormal uterine bleeding: The results of a prospective study. European Journal of Obstetrics \& Gynecology and Reproductive Biology, 244: 134-140 .

5. Fonda J (2011): Ultrasound diagnosis of caesarean scar defects. Australasian Journal of Ultrasound in Medicine , 14(3):22-30.

6. Zafarani F, Ahmadi F, Shahrzad G (2017): Hysterosalpingography in the assessment of congenital cervical anomalies. International Journal of Fertility \& Sterility, 11(2):71-75.

7. Bhagavath B, Lindheim S (2018): Optimal management of symptomatic cesarean scar defects. Fertility and Sterility, 110(3):417-8.

8. Charan J, Biswas T (2013): How to calculate sample size for different study designs in medical research? Indian Journal of Psychological Medicine, 35: 121-126.

9. Jensen R, Thornton R (2003): Early female marriage in the developing world. Gender \& Development, 11(2):9-19.

10. Fiocchi F, Petrella E, Nocetti L et al. (2015): Transvaginal ultrasound assessment of uterine scar after previous caesarean section: comparison with 3Tmagnetic resonance diffusion tensor imaging. La Radiologia Medica, 120(2):228-38.

11. Vikhareva Osser O, Jokubkiene $L$, Valentin $L$ (2010): Cesarean section scar defects: agreement between transvaginal sonographic findings with and without saline contrast enhancement. Ultrasound in Obstetrics and Gynecology, 35(1):75-83.

12. Ofili- Yebovi D, Ben- Nagi J, Sawyer E et al. (2008): Deficient lower- segment Cesarean section scars: prevalence and risk factors. Ultrasound in Obstetrics and Gynecology: The Official Journal of the International Society of Ultrasound in Obstetrics and Gynecology, 31(1):72-7.

13. Schugart $R$, Friedman A, Zhao $R$ et al. (2008): Wound angiogenesis as a function of tissue oxygen tension: a mathematical model. Proceedings of the National Academy of Sciences, 105(7):2628-33.

14. Whaley K, Burt A (1992): Factors influencing wound healing. Muir's Textbook of Pathology, MacSween R, Whaley K (eds). Edward Arnold: London, Pp. $160-$ 161.

15. Pollio F, Staibano S, Mascolo M et al. (2006): Uterine dehiscence in term pregnant patients with one previous cesarean delivery: growth factor immunoexpression and collagen content in the scarred lower uterine segment. 
American Journal of Obstetrics and Gynecology, 194(2):527-34.

16. Monteagudo A, Carreno C, Timor-Tritsch I (2001): Saline infusion sonohysterography in nonpregnant women with previous cesarean delivery: the" niche" in the scar. Journal of Ultrasound in Medicine, 20(10):1105-15.

17. Armstrong V, Hansen $\mathrm{W}$, Van Voorhis $\mathrm{B}$ et al. (2003): Detection of cesarean scars by transvaginal ultrasound. Obstetrics \& Gynecology, 101(1): 61-65 .

18. Fabres C, Aviles G, De La Jara C et al. (2003): The cesarean delivery scar pouch: clinical implications and diagnostic correlation between transvaginal sonography and hysteroscopy. Journal of Ultrasound in Medicine, 22(7):695-700.

19. Bij de Vaate A, Brölmann H, Van Der Voet L et al. (2011): Ultrasound evaluation of the Cesarean scar: relation between a niche and postmenstrual spotting. Ultrasound in Obstetrics \& Gynecology, 37(1):93-9.

20. Gubbini G, Centini G, Nascetti D et al. (2011): Surgical hysteroscopic treatment of cesarean-induced isthmocele in restoring fertility: prospective study. Journal of Minimally Invasive Gynecology, 18(2):2347.

21. Tower A, Frishman G (2013): Cesarean scar defects: an underrecognized cause of abnormal uterine bleeding and other gynecologic complications. Journal of Minimally Invasive Gynecology, 20(5):562-72.

22. Bujold E, Jastrow N, Simoneau J et al. (2009): Prediction of complete uterine rupture by sonographic evaluation of the lower uterine segment. American Journal of Obstetrics and Gynecology, 201(3):320-26. 